DOI: 10.20472/IAC.2018.038.012

\author{
ABANG FAITH MIYANG \\ Higher National Institute of Siantou, Cameroon
}

\title{
MULTIPLE PROJECT ENVIRONMENTS AND MANAGEMENT CHALLENGES
}

\begin{abstract}
:
In the construction industry multiple project environments (MPE) exist where more than one project is managed simultaneously. The driving force behind MPEs is the pragmatic allocation of resources encumbered by uncertain economic times. However, MPEs create management challenges that need to be addressed. For that reason, this paper aims to investigate the challenges in respect to managing MPEs within the construction industry. It essentially reviews state-of-art knowledge in respect to MPEs identifying the rationale behind their development. At this stage it would appear that the interdependency and uncertainty within inputs, processes and outputs are major contributing factors to the MPE problem. It is of note that the majority of these findings were based within the context of developed countries. Hence, this review sets out to inform practitioners from developing countries in respect to lessons learned within more developed countries. This review is expected to lead to further investigations on MPEs and their inherent challenges.
\end{abstract}

\section{Keywords:}

Project management, Construction industry, multiple project environments

JEL Classification: 013 


\section{Introduction}

Organizations are taking management initiatives by shifting the paradigm of project management to the management of multiple projects (Blomquist and Müller, 2006, Pennypacker and Dye, 2002, Evaristo and van Fenema, 1999) as an efficient vehicle to successfully deliver improvements and changes due to the unpredictable economic climate (Shehu and Akintoye, 2010). For the construction industry, it needs to assimilate new steps to intervene with such uncertainties to survive. Thus managers are altering their strategic direction to expand opportunities and expand capacity for marketing, sourcing, introducing new infrastructure and taking advantage of distributed location (Dooley et al., 2005).

Studies on the management of multiple projects are dominated by the high technology industry (Caniëls and Bakens, 2011, Patanakul and Milosevic, 2009, Maylor et al., 2006) specifically on the new product development. Few studies have examined and little analytical attention has been paid to the management of multiple projects environment within the construction industry (Gholipour, 2006, Blismas et al., 2004, Dubois and Gadde, 2002).

Furthermore, most studies have demonstrated the existence of multiple projects environment from the context of developed country. Although studies on construction industry in the context of developing country has been acknowledged in the literature (Ngowi, 2002, Ofori, 2000), little recognition has been given to the multiple project environments within the construction industry. It is important to recognize the management of multiple projects environment from the developing country because the construction industry among countries is different as presented in the cultural studies of the construction projects, firm and site by Baiden and Price (2011). Thus, the complexity of challenges will be different in the level of socio-economic stress, chronic resource shortages, institutional weaknesses and a general inability to deal with the key issues (Ofori, 2000). Therefore, this review builds on and contributions to the work in the multiple projects environment (MPE) within the construction industry. Although studies in the MPE have examined the development of effectiveness in management (Chinowsky et al., 2011, i.e

Patanakul and Milosevic, 2009), there has been lack of an extended study on the challenges that hinder the effectiveness in managing the MPE. This paper will address this issue by reviewing how the assertions about challenges attributed to the MPE within the construction industry have been transformed into lessons to be learned for the developing countries. Consequently, this review provides additional insight into the constructive processes of exploring challenges by explicating the challenges through 
which the uncertainty and interdependency is constructed from the complexity of management.

\section{Multiple project environments}

Multiple project environments (MPEs) have been defined in many ways in the research. To describe the management of MPEs, studies have been premised with terms such as multi-project, portfolio, programmed, macro-project, mega-project, giving the impression of similar meanings (Turner, 2009, Project Management Institute, 2008). The inconsistency in definition has led to limited insights due to confusion and diverse understanding (Shehu and Akintoye, 2010, Milosevic, 2009) into the relationship of MPEs and their challenges. The definition of the MPE in this review reveals some features that best describe the nature of the construction industry. Initially, MPEs was referred to, "an organizational level environment in which multiple projects are managed concurrently" (Patanakul and Milosevic, 2009, p. 217). However, this definition needs to be extended not to focus only on more than one project managed simultaneously, but also at various locations (Evaristo and van Fenema, 1999), on the possibility of involvement from multiple organizations (Dubois and Gadde, 2002)

These two features of multiple projects at various locations and involves multiple organizations are important in defining MPEs. The first feature stressed on various locations because within the construction industry, projects are influenced by geographical location which includes international and domestic distribution whether in a local region or elsewhere. This distribution is due to the potential benefits of the physical location and where professionals are involved in the project operation location (Zavadskas et al., 2004). One project can be performed in several sites concurrently, as long as the correspondent actions share the same objectives (Evaristo and van Fenema, 1999). The management of these projects is assumed to be either centralized or distributed located in any of the sites or nodes. The challenge of project's location of multiple projects is related to the focus on the co-ordination mechanisms, with the option of either focusing on inter-site or boundary spanning across sites, or concentrate on intrasite or boundary spanning across projects (Hashim and Chileshe, 2012).

The second feature originated from the construction management which is complicated by several organizations involved in the supply chain. The organizations are also engaged in other projects in which they have to coordinate their activities and resources with different sets of organizations. This affiliation shows that an organization is capable in managing more than one project simultaneously in the construction industry (Dubois and Gadde, 2002) and supports project-based structures (Söderlund, 2004). The increased use of project-based structures defines the nature of multiple project environments with the involvement of multi-project organizations. 
From these features, the representation of challenges instigated from the complexity in managing multiple projects could be illustrated. For example, the projects located in multiple locations will focus on the co-ordination mechanisms, on single unit without segregating the projects into multiple units in sharing the projects goal and objectives even though they are widely distributed from each other (Desouza and Evaristo, 2004). On the other hand, projects which involves with multiple organizations will easily create conflict between the team mates, and impede the establishment of "organization culture" of multiple projects environment particularly between different levels of management or between other projects,

\section{Project Outputs}

Typically, a key reason that an organization implements the MPE is to achieve better efficiency and management of projects. MPE can only be effectively managed in any organization if there is certainty in project manager's expectation and the project's benefits. The expected output from project managers are meeting time, cost, performance, and satisfying customers and effective use of organizational resources (Patanakul and Milosevic, 2009, John et al., 2000). In the meantime, the project's benefits should be established in the form of potential of project output (Shehu and Akintoye, 2010). Uncertainty about a project's output and benefit can let other projects take priority attention that is not favorable for effectiveness in managing multiple projects.

\section{Discussion}

Overall, the emerging perspective on challenges provides important insights into the effectiveness in managing the MPE. This literature review has recognized the attributes of MPEs, which is the management of multiple projects simultaneously (Patanakul and Milosevic, 2009). An example is the assignment of a residential construction project, building construction project and an alteration or improvement of facilities project to one project manager. It also has identified additional attributes of MPE which should be considered to describe the nature of construction industry. One new attribute is the management of multiple projects in multiple locations (Desouza and Evaristo, 2004). One project could be in different region, states, or even country to require benefits from different locations such as close cooperation of professionals or to take advantage of the location. Another attribute is the involvement of multiple organizations that connect stakeholders' actions to the development of projects organization (Dubois and Gadde, 2002). For example, in one project many organizations are all involved in operations at a construction site which contribute to the resources of various kinds. The organizations also involve in other projects that might cooperate with similar or other organizations. Therefore, each organization needs to consider different dimensions of co-ordination 
within the individual project, among different construction projects and inter-firm coordination with other projects.

These attributes should be considered as conditions and moderators of challenges in managing multiple projects. These moderators are uncertainty and interdependency of management that shaped the complexity of the environment (Grant and Parker, 2009) which influence on the organizational input, management processes and output of projects (Hashim and Chileshe, 2012, Patanakul and Milosevic, 2009). Organizational input is the earliest process of the project lifecycles which involves in the initiation or conceptual of the project (Patanakul et al., 2010). The outcomes of uncertainty in the organizational input include project selection in understanding the project priority, matched with the ability of project managers and the project assignments and resource allocation. The management processes is the continuing process throughout the projects which support monitoring and control activities (Project Management Institute, 2008). Uncertainty in the management process takes account of effective communication, leading groups of projects in resolving problems, information sharing and multitasking. While the project output is looking into the overall success of the projects (Patanakul et al., 2010) focus on the project manager's expectations and project benefits.

However, interdependency mainly occurs in the process stage focused on driving the execution of projects (Project Management Institute, 2008) where single projects are manage simultaneously follow by inter-project interactions. Interdependency is important in project management processes for adjusting and linking schedules to match available resources, and removing unnecessary variation in workloads of project managers. Table 1 summarize the discussion on the challenges in the MPE 
Table 1: Summary of the literature related to the challenges in MPEs

\begin{tabular}{|c|c|c|}
\hline MPE / Challenges & Uncertainty & Interdependency \\
\hline Organizational Input & $\begin{array}{l}\text { Project selection } \\
\text { (Patanakul and Milosevic, } \\
\text { 2009) } \\
\text { To understand the project } \\
\text { priority, match between the } \\
\text { ability of project managers } \\
\text { and the project assignments } \\
\text { Resource allocation } \\
\text { (Elonen and Artto, 2003, } \\
\text { Fricke and Shenbar, 2000) }\end{array}$ & \\
\hline Management Processes & $\begin{array}{l}\text { Lead group of projects } \\
\text { (Patanakul and Milosevic, } \\
\text { 2009, Patanakul and } \\
\text { Milosevic, 2008) } \\
\text {-Problem solving } \\
\text { (Engwall and Jerbrant, 2003) } \\
\text {-Information sharing } \\
\text { (Elonen and Artto, 2003) } \\
\text {-Multitasking } \\
\text { (Patanakul and Milosevic, } \\
\text { 2008) } \\
\text { Communication } \\
\text { (Lycett et al., 2004) }\end{array}$ & $\begin{array}{l}\text { Management of single } \\
\text { projects (Shehu and Akintoye, } \\
\text { 2010) } \\
\text {-Project Management Process } \\
\text { (Hashim and Chileshe, 2012) } \\
\text { To adjust and link } \\
\text { schedules to match available } \\
\text { resources, and remove } \\
\text { unnecessary variation in } \\
\text { workloads of project } \\
\text { managers } \\
\text { Inter-project interactions } \\
\text { (Milosevic, 2009, Fricke and } \\
\text { Shenbar, 2000) }\end{array}$ \\
\hline Project Output & $\begin{array}{l}\text { Project manager's expectation } \\
\text { (Patanakul and Milosevic, } \\
2009, \text { John et al., 2000) } \\
\text { Project's benefit } \\
\text { (Shehu and Akintoye, 2010) }\end{array}$ & \\
\hline
\end{tabular}

\section{Contribution}

From a theoretical point of view this literature review broadened the project management knowledge in respect to relationships within multiple projects environments and their challenges. The identification of the challenges should be of interest to researchers within 
risk management in respect to multiple projects environments and this should be recognized as being an essential part of the construction industry. The practical contribution of this study would be through the exploration of challenges in the multiple projects environment that

Likely to confront project managers. It should be kept in mind that project management is a core competence and the building of project capabilities thus this exploration is assisting in identifying and mitigating the future risks in managing multiple projects. It also aims to improve the effectiveness and efficiency of project managers by providing findings that serve as a basis for developing strategies within organizational management.

Moreover, in light of globalization, national and organizational cultures may play an increasingly important role in the MPE development. Within the context of developed countries a comparison guideline should be formulated for the management of multiple projects. National and organizational cultures can play an important role in influencing the challenges in MPEs. However, the lack of in-depth knowledge of how the global environment and the differences in cultures across societies and organizations affect MPEs thus creates challenges that hinder the effectiveness of management. Therefore, it is hoped that this study will inspire other researchers to provide understandings for the development of MPEs not only within the context of developed countries but also for the developing world.

\section{Conclusions}

The unpredictability of the current economic climate has directed the development of MPEs. Most studies on MPEs focus on newly development products from the manufacturing industry where the processes are mainly high risk with concurrent processes. However, in the construction industry, the MPE is part of the inherent nature of industry practice, albeit with a lack of research that establishes the understanding of the phenomena. At this stage, project management practice in MPEs has not adopted an explicit way to identify and select the right management style. This study suggests that the understanding of challenges will give rise to adopting the right approach for the right project.

The trends of increasing interdependence and uncertainty in managing projects are emerging which creates challenges for managing the MPE effectively. Ultimately, there is a need for better understanding of challenges in supporting the development of effective management. To achieve this understanding, it may be necessary to consider the various perspectives and challenges in parallel. These advances in MPE research are beginning to answer calls to investigate the challenges and its implications for management. Even 
though this study applies only to a subset of organizations and industries, challenges in MPEs are relevant to understand and change the experiences and behaviors of managers within the project management discipline.

In summary, what is missing at this point is a comprehensive framework of the challenges and effectiveness in managing the MPE. The need of a management framework is to capture the overall characteristics of the MPE in the construction industry. It will also assist in identifying conditioning variables that influence the relationship and the outcomes they influence, and a core set of mediators and moderators for these relationships. The evidence reviewed above not only aims to provide a platform of progressing into empirical research within developed countries but also as a function of lessons learned to develop a comprehensive study on the development of multiple projects environments within developing nations.

\section{References}

Aritua, B., Smith, N. J. \& Bower, D. 2009. Construction client multi-projects - A complex adaptive systems perspective, International Journal of Project Management, vol. 27, no. 1, pp. $72-79$.

Baiden, B. K. \& Price, A. D. F. 2011. The effect of integration on project delivery team effectiveness, International Journal of Project Management, vol. 29, no. 2, pp. 129-136.

Bankvall, L., Bygballe, L. E., Dubois, A. \& Jahre, M. 2010. Interdependence in supply chains and projects in construction, Supply Chain Management: An International Journal, vol. 15, no. 5, pp. 385-393.

Blismas, N., G., Sher, W., D., Thorpe, A. \& Baldwin, A., N. 2004. Factors influencing project delivery within construction clients' multi-project environments, Engineering, Construction and Architectural Management, vol. 11, no. 2, pp. $113-125$.

Blomquist, T. \& Müller, R. 2006. Practices, roles, and responsibilities of middle managers in program and portfolio management Project Management Journal, vol. 37, no. 1, pp. 52-66.

Caniëls, M. C. J. \& Bakens, R. J. J. M. 2011. The effects of project management information systems on decision making in a multi project environment, International Journal of Project Management, vol. 30, no. 2, pp. 162-175.

Chinowsky, P., Taylor, J. E. \& Di Marco, M. 2011. Project network interdependency alignment: new approach to assessing project effectiveness, Journal of Management Engineering, vol. 27, no. 3, pp. 170-178. 
Cooke-Davies, T. 2002. The "real" success factors on projects, International Journal of Project Management, vol. 20, no. 3, pp. 185-190.

Danilovic, M. \& Sandkull, B. 2005. The use of dependence structure matrix and domain mapping matrix in managing uncertainty in multiple project situations, International Journal of Project Management, vol. 23, no. 3, pp. 193-203.

De Orue, D. A. O., Taylor, J. E., Chanmeka, A. \& Weerasooriya, R. 2009. Robust project network design, Project Management Journal, vol. 40, no. 2, pp. 81-93.

Desouza, K. C. \& Evaristo, J. R. 2004. Managing knowledge in distributed projects, Communication of the ACM, vol. 47, no. 4, pp. 87-91.

Dietrich, P. \& Lehtonen, P. 2005. Successful management of strategic intentions through multiple projects Reflections from empirical study, International Journal of Project Management, vol. 23, no. 5, pp. 386-391.

Dooley, L., Lupton, G. \& Sullivan, D. O. 2005. Multiple project management: a modern competitive necessity, Journal of Manufacturing Technology Management, vol. 16, no. 5/6, p. 466.

Dubois, A. \& Gadde, L.-E. 2002. The construction industry as a loosely coupled system: Implications for productivity and innovation, Construction Management and Economics, vol. 20, no. 7, pp. 621-631.

Elonen, S. \& Artto, K. 2003. Problems in managing internal development projects in multi-project environments, International Journal of Project Management, vol. 21, no. 6, pp. 395-402.

Engwall, M. \& Jerbrant, A. 2003. The resource allocation syndrome: The prime challenge of multi-project management, International Journal of Project Management, vol. 21, no. 6, pp. 403-409.

Evaristo, R. \& van Fenema, P. C. 1999. A typology of project management: Emergence and evolution of new forms, International Journal of Project Management, vol. 17, no. 5, pp. 275-281.

Fricke, S. E. \& Shenbar, A. J. 2000. Managing multiple engineering projects in a manufacturing support environment, IEEE Transactions on Engineering Management, vol. 47, no. 2, pp. 258-268.

Gholipour, Y. 2006. 'Multi-Project Resources Procurement in the Construction Industry', in McDermott, P. \& Khalfan, M. M. A., eds., Sustainability and Value Through Construction Procurement, Salford, United Kingdom, 29 November - 2 December 2006, Salford Centre for Research and Innovation (SCRI), University of Salford, pp. 172-181.

Görög, M. 2011. Translating single project management knowledge to project programs, Project Management Journal, vol. 42, no. 2, pp. 17-31. 
Grant, A. M. \& Parker, S. K. 2009. Redesigning work design theories: The rise of relational and proactive perspectives, ACADEMY OF MANAGEMENT ANNALS, vol. 3, no. 1, pp. 317-375.Australasian Journal of Construction Economics and Building Conference Series Hashim, N.I., Chileshe, N., and Baroudi, B. (2012) 'Management challenges within multiple project environments: Lessons for developing countries', Australasian Journal of Construction Economics and Building, Conference Series, 1 (2) 21-31 30

Griffin, M. A., Neal, A. \& Parker, S. K. 2007. A new model of work role performance: Positive behavior in uncertain and interdependent contexts, Academy of Management Journal, vol. 50, no. 2, pp. 327347.

Hashim, N. I. \& Chileshe, N. 2012. Major challenges in managing multiple project environments (MPE) in Australia's construction industry, Journal of Engineering, Design and Technology, vol. 10, no. 1, pp. 72-92.

John, A. K., Chung-Li, J., Abdallah, S. F. \& Wahib, G. J. 2000. Project manager workload--assessment of values and influences, Project Management Journal, vol. 31, no. 4, p. 44.

Laslo, Z. \& Goldberg, A. I. 2008. Resource allocation under uncertainty in a multi-project matrix environment: Is organizational conflict inevitable?, International Journal of Project Management, vol. 26, no. 8, pp. 773-788.

Lycett, M., Rassau, A. \& Danson, J. 2004. Programme management: a critical review, International Journal of Project Management, vol. 22, no. 4, pp. 289-299.

Martyn James, H., Paul William, F., Martin, S., Carol, K. H. H. \& Patrick Sik-Wah, F. 2008. 'The Role of Project Managers in Construction Industry Development', AACE International Transactions, DE141DE149.

Maylor, H., Brady, T., Cooke-Davies, T. \& Hodgson, D. 2006. From projectification to programmification, International Journal of Project Management, vol. 24, no. 8, pp. 663-674.

Meredith, J. R. \& Mantel, S. J. 2003. Project Management A Managerial Approach, 5th ed., New Jersey: John Wiley \& Sons Inc.

Milosevic, D. Z. 2009. Program management for improved business results, New Jersey: Wiley.

Mitleton-Kelly, E. 2003. Complex systems and evolutionary perspectives on organizations: the application of complexity theory to organizations, Amsterdam: Pergamon. 
Morgeson, F. \& Humphrey, S. 2008. Job and team design: Toward a more integrative conceptualization of work design, Research in Personnel and Human Resources Management, vol. 27, no. Journal Article, pp. 39-91.

Ngowi, A. 2002. Challenges facing construction industries in developing countries, Building Research \& Information, vol. 30, no. 3, pp. 149-151.

Ofori, G. 2000. 'Challenges of construction industries in developing countries: Lessons from various countries', in Proceedings of the 2nd international conference in developing countries: challenges facing the construction industry in developing countries, Gabarone, Botswana, 15-17 November 2000.

Olford, W. J. 2002. 'Why is multiple project management hard and how can we make it easier?' in Pennypacker, J. S. \& Dye, L. D., eds., managing multiple projects: planning, scheduling and allocating resources for competitive advantage, New York: Marcel Dekker, Inc. 